\title{
Porque el humanismo es hoy obligadamente un ecologismo radical y profundo
}

Una palabra ilumina mi investigación: comprender.

Marc Bloch

Jose Luis Talancón E.

Uno de los debates más intensos en las universidades del mundo actualmente, gira en torno a pensar el cambio de época y el destino del hombre y la noción de persona concreta en un proceso de abstracción y mundialización que aparece desbocado y fuera de control, particularmente por las manifestaciones del calentamiento global. Por ello creo necesario abordar algunos de los núcleos problemáticos de la filosofía desde su origen: ¿Determinismo o Azar ? ¿Estructura o libertad? ¿Cómo se ha tejido la realidad con objetos reales o con formas simbólicas? ¿Qué es más real: el sujeto que ha venido construyendo al objeto y o el objeto que induce y transforma al sujeto? En la Técnica -decía Martin Heidegger,- hay una parte de la verdad, pero a costa del olvido del Ser. Las intenciones y la racionalidad por escapar de la ignorancia, la escasez y la injusticia, trajeron consecuencias negativas que en última instancia favorecieron más al poder que a quienes regulaba y arbitraba ese poder. Asimismo, el olvido del Ser puede interpretarse como una condición en la cual el invento se revierte negativamente al inventor, para acabar configurándose una inversión entre medios y fines. Ante las consecuencias no deseadas de la racionalidad, creo necesaria una reflexión cuestionante y abierta sobre las enormes potencialidades que han cobrado los objetos en la Era Técnica, justo cuando el extravío racional, la desorientación social y el incremento e intensidad de los riesgos ambientales y epidemiológicos se hacen patentes bajo el umbral de un cambio climático inegable e ineludible. Esto nos lleva a formularnos otra pregunta de carácter histórico: ¿Qué ha estado más presente en la constante confluencia de muchas humanidades y su transformación de homínidos en hombre modernos: el ansia de dominio y violencia o la sed de emancipación? Según Lewis Mumford, traemos ya desde Arquímedes una tendencia destructiva, como una ecuación en una nube alrededor de la astucia y racionalidad que nos puede llevar al descenso, hacia la degradación total: 
“¿Acaso la asociación de un poder y una productividad desmesurados con una violencia y una destructividad igualmente desmesurados es algo puramente accidental"? ${ }^{1}$ Desde esta perspectiva pareciera que coinciden y se afectan mutuamente cierta animalidad con astucia racional. Lejos de que se haya logrado domar la animalidad implícita en los seres humanos a través de siglos de servidumbre, pareciera que se ha incrementado la pasión bestial de dominio y poder de las clases dominantes. El siglo XX, cumplió la profecía de Nietzsche en cuanto a la generalización y expansión de la voluntad de poder, como estructuras biológicas del paleolítico subsisten y se reactivan como poderosas endorfinas de una naturaleza humana caracterizada por su amor a la guerra. Se han requerido multiplicar los Arquímedes, para llegar a experiencias radicales como las que vivió la humanidad durante el siglo XX.

Durante los mil años que separan a la Antiguedad del inicio de la Edad Moderna, la contemplación fue una actitud espiritual en la cual el que contemplaba se dejaba iluminar y transformar por lo contemplado. Y a mediados del siglo XVI fue cuando la contemplación comenzó a dejar su lugar a la acción, con la cual el protestantismo y la técnica alteraron de manera radical la relación sujetoobjeto, a partir de nuevas interpretaciones del objeto de contemplación, nuevas exégesis que transformaron al sujeto mentalmente por su manera de comprender al mundo y mirar a Dios, actitudes espirituales que coincidieron con nuevas capacidades productivas derivadas de la proto-manufactura y la técnica que, desde su fase artesanal, despejaron el camino a mecanismos protoindustriales que revolucionaron las formas de producir riqueza material: desde entonces el mundo es habitado por El espíritu del capitalismo, tal como lo describiera Max Weber, y de lo que se trata es de transformar el mundo en riqueza para mayor gloria de Dios. Los cinco siglos siguientes, desembocaron en lo que estamos viviendo a diario: un proceso de destrucción, contaminación y deforestación imparables, migraciones, explotación de grandes masas, megaurbanización, declive y desregularización de la economía mundial.

Antes de dejarnos llevar por una realidad apocalíptica, vayamos por partes. Inicialmente podríamos señalar los cinco grandes escenarios por los cuales esta relación sujeto-objeto experimenta cambios ontológicos y epistemológicos, que reflejan los modos en que se afectan mutuamente el sujeto y el objeto. Así tenemos que Dios, Phisis, (naturaleza) Historia, Hombre y Técnica, han constituído los ejes de evolución del pensamiento humano o si se prefiere, los

1 Lewis Mumford. El pentágono del poder. El mito de la máquina (dos). Edit. Pepitas de calabaza. Madrid 2011. pp 416. 
escenarios por los que la materia- en el privilegiado lugar que es el cerebro del hombre- ha venido autocomprendiendose. ${ }^{2}$

Por este camino podríamos coincidir con Kostas Axelos ${ }^{3}$ para quien, la Prehistoria, la Antigüedad, la Edad Media y la Edad Moderna son fases de develamiento del pensamiento humano. Es decir que el pensamiento humano ha ido develando, desocultando respectivamente a Dios, a la Naturaleza, a la Historia y en la Edad Moderna y Contemporánea, el espíritu humano no acaba de desocultar y pensar al hombre ni a la Técnica. Entendida como forma de develamiento, des-ocultación de la verdad, la Técnica es entendida como el lugar donde la verdad es emplazada. Como equivalente al espacio donde ocurre el fín de la metafísica. El ocaso de Dios y el alba del Ser: a uno llegamos tarde y a otro muy temprano.

A partir de esta perspectiva, podríamos seguirle la huella a la construcción del humanismo, precisamente a partir de diferentes momentos en la historia en los cuales tiene lugar una mezcla, sabia combinación entre los poderes y los saberes, cuando el conocimiento penetra a la sociedad, como la sangre irriga al cuerpo. La acumulación de conocimiento en cada una de esas fases, ha permitido a la sociedad dar saltar epistemológicos y ontológicos a nuevas formas de comprensión del mundo, pero también hacia formas más abiertas y justas de la organización social. Así comprendemos el gran significado ético de momentos del humanismo con figuras como Prometeo, cuando le pronuncia a Hermes, el mensajero de Zeus: quiero que sepas que yo no cambiaría mi miseria contra tu esclavitud. Prefiero estar atado a esta roca que ser el mensajero fiel de Zeus tu padre ${ }^{4}$ Aquí comienza la rebeldía del humanismo, como un sentimiento arraigado en el corazón de los hombres que se va ir cristalizando en racionalidad emancipadora, en idea revolucionaria, conforme cambian los escenarios, se complejizan los saberes y se hace más sutil el ejercicio del poder. Si observamos con detenimiento, en realidad el humanismo surgió como una defensa de los hombres ante las propias creaciones de los hombres. Una extraña dialéctica en

2 Decía Federico Engels, que el único lugar donde la naturaleza cobra conciencia de sí-misma, es en el cerebro del hombre. Introducción a la Dialéctica de la Naturaleza, Obras Escogidas, Edt. Progreso y Cultura Popular. México 1965. pp 359.

3 El último heideggeriano de izquierda, este gran pensador solitario y trágico greco-francés, ha desarrollado su filosofía en una trilogía de nueve vólumenes, que nos lleva de Heráclito a Marx y a la edad de la técnica a la culminación de la historia de Occidente. Para él, el hombre es lo que está en juego en el mundo y el mundo es para el hombre la apuesta suprema. Al margen de modas e ideologías, Axelos advierte el advenimiento de un pensamiento "cuestionante, planetario, y mundialmente errante". Ediciones Minuit ha publicado toda su obra. En español, Fontanella y el Fondo de Cultura Económica han publicado algunos de estos volúmenes.

4 Lecourt Dominique, Prométhee, Faust, Frankenstein, Fundements imaginaires de l'éthique. Synthélabo Paris 1996. 
la que las creaciones y pasiones objetivadas de los hombres se rebelan contra los hombres, sean estos dioses o máquinas, estados o mercados, revoluciones o iglesias.

Y es que cuando digo que el humanismo originalmente es más un resultado de las emociones y los sentimientos que de la razón, afirmo que quien no se conmueve con el sufrimiento y la miseria del otro, no alcanza a comprender lo que significa el ser humanista ni alcanza a comprender el significado de conceptos como fraternidad, solidaridad, caridad en otro tiempo conocida como una virtud teologal. Por eso cuando los intelectuales anglosajones, norteamericanos y europeos, nos dicen a los latinoamericanos que no hacemos ciencia sino ideología, lo que están ignorando es que el conocimiento no sólo es producto de la medición sino que el conocimiento también es resultado del sentimiento, de una ética de sentido común y sensatez. Consideremos simplemente que el sentimiento de lo sagrado ha precedido en miles de años al conocimiento científico.

Un mundo en el que todos queden incluídos y nadie se quede en la orfandad y a la intemperie es una aspiración que fue tejiendo un delgado hilo ético que ha cruzado la historia de Occidente a través de los siglos, dejando un tapiz a través de cuatro actitudes espirituales originales, anteriores a la invención de la ciencia moderna: El amor a Dios de los judíos; la pasión a la ingeniería, el derecho y el poder de los romanos; el amor al prójimo de los cristianos y por último el amor a la verdad y el conocimiento de los griegos. Es decir, nos podemos hacer una idea del hombre por lo que cree, por lo que hace, por lo que practica o por lo que busca. Esta última es fundamental para ubicar las limitaciones de la teoría y la práctica individuales y colectivas, porque en su humilde actitud, reconoce la escasez que caracteriza la condición humana inicial: escaza, ignorante y oscura. Por eso la idea de que el hombre no nace, sino que se hace en la búsqueda de respuestas, es en el fondo la idea ilustrada y humanista que reconoce que es el conocimiento lo que transforma la espiritualidad humana, de ahí lo sagrado de la Paideia griega o la mística de las universidasdes medievales o la fuerza transformadora de las escuelas politécnicas del XIX.

Podríamos afirmar que en el largo transcurrir de más de quinientas generaciones desde el mundo clásico hasta nuestros días, a lo largo de tres milenios, estas cuatro actitudes se confundieron y se distanciaron hasta cristalizar en nuevas posturas espirituales y en tremendas ideologías desarrolladas en el Renacimiento y posteriormente en los siglos XVIII y XIX, con figuras como la del Fausto de Marlowe de 1587, ó el mismo Fausto de Goethe de 1832. Héroes del humanismo que revelan el gran paraíso a construir aquí en la tierra, que aguarda a los espíritus aventureros y libertarios, caminos no excentos de riesgos. 
A la idea rebelde que la figura de Prometeo aporta, se suma la idea judeocristiano, pero con una idea de hombre creado y humillado por un Dios autoritario que le gusta ponerlo a prueba. Si bien es una idea de hombre muy contradictoria, su gran contribución es la valoración moral del sufrimiento, la cual tendrá un gran arraigo en la tradición Occidental y que se desdoblará hasta una ética que recoge el marxismo. Pero antes de entrar a ese tercer gran momento del humanismo que constituye el marxismo, hagamos una pequeña escala en el Renacimiento.

La complejidad vino precisamente a partir de la aportación que hiciera por un lado René Descartes y por otro lado Francis Bacon al construir cada uno por su lado una teoría y una práctica del actuar humano, gracias a la conexión entre el cerebro y la mano. Mediante una larga evolución biológica que culminó en el uso cultural de energías disponibles y en el lenguaje, se legitimó la idea de explotar una naturaleza feminizada de recursos infinitos. Esta idea masculina y misógina se trasladó fácilmente a un esquema de dominación social para garantizar la fuente de energía animada de los hombres. Se actúa sobre el curso natural de las cosas y sobre el imaginario social de los hombres: en suma la metafísica del progreso sienta sus reales para consumir las dos dimensiones naturaleza y sociedad. Consecuencia directa: al artificializarlo todo, el ser humano altera por así decirlo las leyes de la evolución al contribuir a frenar la biodiversidad (obsérvese la cantidad de especies en peligro de extinción como consecuencia directa o indirecta de la acción humana) e influye en el proceso entrópico a través de la invención de nuevas y cada vez más potentes formas de energía anteriormente utilizables: carbón, petróleo, electricidad, fisión nuclear, hasta quimeras biológicas derivadas de la posibilidades abiertas por el mapeo integral del genoma humano.

Francis Bacon fue un personaje considerado como el profeta de nuestro mundo científico-tecnológico. En unos cuantos trabajos que hicieron historia, señaló los contornos del mundo en el que la ciencia y la técnica ya no estarían en manos de unos aficionados desperdigados, como había sucedido hasta sus propios días, alrededor de 1600, sino que se transformarían en una empresa colectiva organizada internacionalmente, financiadas por las autoridades, con conferencias y publicaciones sistemáticas, tal como lo hace la comunidad científica internacional en nuestros días. Sólo así podría conseguirse un pleno dominio de la naturaleza. Al final de su vida, escribió Nova Atlantis, La Nueva Atlántida, publicada tras su muerte. En esta obra se traza el proyecto del instituto central de una utópica isla Bensalem, donde se fabrican incluso nuevas especies biológicas. ¿Estaríamos cerrando el ciclo que abrió Bacon, después de haberse confundido capitalismo, emancipación social y perspectivas científicas de la 
vida? ¿Aparecería ahora si con toda intensidad la noción de riesgo derivado del desencuentro entre los vínculos que construyeron Occidente?

Uno de los frutos que dio esta compleja amalgama de las diferentes actitudes originales y posteriores ramificaciones y corrientes de pensamiento renacentista, fue la idea del respeto a la persona humana, que llega al siglo XVIII por la vía de la política y que gira en torno a la sacralidad que el cristianismo había postulado en la persona humana y que la llustración a través del liberalismo, reiteró bajo la consagración de los Derechos del hombre y del ciudadano de 1792. Esas bases axiológicas que sostienen el edificio de la civilización se están sacudiendo, se están cimbrando, porque están resistiendo el enfrentamiento - al final del ciclo de la modernidad - con la técnica y el mecanicismo, la máquina, a través del incremento de los riesgos inmediatos y globales, personales y colectivos. Hoy por hoy, constituye el gran problema al que nos enfrentamos. ¿Por qué? "Porque la civilización Occidental, en su última fase de progreso, ya no es conciente de la personalidad individual, y nada permite ya esperar que alguna vez llegue a serlo. Esta sociedad sólo conoce algunas de las dimensiones de la persona humana. El Occidente ha creado una sociedad semejante a la máquina. Obliga a los hombres a vivir en el seno de la sociedad y a adaptarse a las leyes de la máquina. Cuando los hombres se parezcan a las máquinas hasta el punto de identificarse con ellas, entonces no quedará ya hombre sobre la tierra." Estaríamos ante una creencia desdibujada de la persona humana — como lo señaló el filósofo existencialista católico Gabriel Marcel— ¿Es hoy la persona humana un residuo desvitalizado, incluso esclerotizado, una creencia en sí misma caduca? ¿Cómo se tejió esta trama que en nuestros días pareciera acercarse a un desenlace ineludible? Esta pregunta nos lleva a construir un sistema teórico que permita vincular el destino de la persona humana sometido a una maquinaria global productora de alto riesgo.

Pasemos ahora a ese tercer gran momento del humanismo que significó la aportación de Karl Marx, para encontrar un hilo explicativo central para nuestro interés cuando planteó en la Miseria de la Filosofía uno de los núcleos temáticos básicos del marxismo: "al adquirir nuevas fuerzas productivas, los hombres mudan su sistema de producción, y al mudar el sistema de producción, la manera de ganarse la vida, mudan todas sus relaciones sociales. El molino de mano nos dará

5 Gabriel Marcel, Los hombres contra lo humano, Caparrós Editores. Madrid 1951. Dice este gran filósofo humanista en relación a uno de los grandes valores de la llustración: La igualdad recae sobre lo abstracto; no son los hombres quienes son iguales, pues los hombres no son triángulos o cuadriláteros. Lo que es igual, lo que ha de ser establecido como igual, no son en absoluto seres, sino derechos y deberes que esos seres están obligados a reconocerse unos a otros, sin lo cual lo que reina es el caos, la tiranía con todas sus horribles consecuencias- la primacía de lo más vil sobre lo más noble. 
la sociedad con el señor feudal; el molino de vapor, la sociedad con el capitalismo industrial... Hay un movimiento continuo de acrecentamiento en las fuerzas productivas, de destrucción de las relaciones sociales, de formación en las ideas". ${ }^{6}$

¿A qué sujetos correspondería la actual oleada de conocimientos, disolución de Estados nacionales y conformación de bloques geoeconómicos actuales? ¿Avances científicos que amenazan la organización social? La interacción y correlación de fuerzas que ocurre entre nuevos objetos y nuevos sujetos pasa por le reorganización y concentración de la propiedad y el poder, pasa por la violencia desatada que implican la destrucción de más de 650 mil hectáreas de bosque anuales en este país, pero esta idea se asocia trágicamente a la incapacidad del Estado de Derecho para frenar los crímenes de más de 500 mujeres en las ciudades de nuestros países, en donde emerge la irracionalidad y la barbarie de nuestras formas actuales de vida colectiva.

Creo que a partir de reconocer y vincular eso que Marx llamó el resultado de la relación entre fuerzas productivas y relaciones sociales de producción, estaríamos en mejores condiciones teóricas de explorar las aspiraciones éticas que apuntalan la búsqueda de la verdad, las construcciones socio-históricas derivadas del conocimiento de las leyes de la naturaleza y de la naturaleza humana. Buscar al hombre transformado por sus obras y creaciones. Indagar sobre las profundas contradicciones que la modernidad ha troquelado en la humana naturaleza y detectar cómo fue que la racionalidad instrumental, aplicada a la dominación de la naturaleza transitó a la dominación asimétrica y violenta de la sociedad. Sin duda el humanismo forma parte de los claros, más que de los momentos oscuros de la historia.

De otra forma no podríamos explicar la evolución de la sociología en su balance sobre las formas en que se han modelado y desplazado las organizaciones sociales, los conflictos por el poder, el manejo político de Dios en la Antigüedad, o más aún el paso mito-lógico a las grandes invenciones políticas que como el Estado y el mercado han reducido pero también han ampliado y multiplicado esos conflictos. Una conquista del siglo XVIII es que abrió la participación de los actores sociales, la idea de pueblo como nuevo actor cambia las condiciones, que son neutralizadas por formas más sutiles del control social.

En suma, podríamos a la manera de Benedotte Groce leer la historia como una hazaña de la libertad, como un despliegue que construye la autoconciencia

6 K. Marx, Miseria de la filosofía. Orbis Barcelona. 1984. Cabe recordar que en el calendario filosófico propuesto por Marx, es Prometeo quien ocupa el primer lugar entre los santos y los mártires. 
apuntando a la posibilidad de perfeccionar la vida humana. Postular que son las condiciones históricas específicas las que cada generación prepara, consolidar esa idea clásica de humanismo como clave de un proyecto común con destino deseado colectivamente, a partir de insisto, ser concientes de lo que significa la gran conquista para la libertad humana los grandes descubrimientos sobre las leyes del universos micro y macrocósmico que los hombres han alcanzado para mejorar sus condiciones de estar en el mundo.

Como podemos observar, han sido muchos los cambios que en la historia de la relación entre sujeto y objeto, el hombre y sus grandes creaciones producto de su imaginación locuaz ${ }^{7}$, o producto de su astucia, de su formas de producir, o sus formas de creer. Todas ellas han contribuído a cambios que el hombre se ha forjado con su idea de Dios, sus representaciones de la naturaleza, de sí mismo, y cuando estamos frente a los poderes de la Técnica ${ }^{8}$, tenemos que reconocer que estamos en proceso de digerir su potencial con muchas desventajas que solo pueden ser aclaradas desde las ciencias sociales, pues, como señalaba J. Nehru ${ }^{9}$ por si solas la tecno-ciencia no puede resolver los problemas que plantean el hambre y la pobreza, la insalubridad y el analfabetismo, la superstición, las costumbres y tradiciones que paralizan, esquemas de producción y distribución que generan derroche de recursos, y sin embargo ¿quién podría permitirse ingnora la ciencia hoy? El problema está en las formas sociales de organización que ahogan y neutralizan una utilización más racional y humanista de sus aplicaciones y potencialidades.

Hoy como en el siglo XIX, todo parece llevar en su seno su propia contradición, vemos que las máquinas, dotadas de la propiedad maravillosa de acortar y hacer más fructifero el trabajo humano, provocan el hambre y el estrés de las grandes multitudes urbanas. Las fuentes de riqueza recién descubiertas -_llámense comunicación por satélite, informática o biotecnología, aplicaciones laser, energía nuclear - se convierten por arte de un extraño maleficio, en fuentes de privaciones, conflictos sociales y asimetrías que agudizan la desigualdad social. El dominio del hombre sobre la naturaleza está desde hace tiempo planteando efectos contraproducentes, saturaciones y grandes riesgos propios de una naturaleza sofocada que simplemente está respondiendo al rompimiento de los ecosistemas y alteraciones de sus ciclos y una sociedad que se encuentra al

7 Jorge Luis Borges decía que las religiones eran una especie de elementales formas de ciencia ficción.

8 Aquí es necesario precisar que Técnica con mayúscula comprende a la misma ciencia. Si decimos que la Era Moderna es la Era de la Técnica, es porque constituye la síntesis teóricopráctica más trascendente del pensamiento humano y una de sus más grandes herramientas de emancipación y motivos de optimismo moderado.

9 Jawaharlal Nehru (1889-1964) fue primer ministro de la India Independiente. 
margen de las aplicaciones científicas y sus consecuencias. No podemos olvidar que como bien señala Beck"Sin racionalidad social, la racionalidad científica está vacía; $\sin$ racionalidad científica la racionalidad social está ciega". ${ }^{10}$

Regresando a Kostas Axelos, nos encontramos en la era Planetaria, en la cual el pensamiento no agota su reflexión intramundana con la técnica. En la era de la técnica planetaria, la Modernidad tardía comparece como el umbral temporal donde se produce la expansión de las opciones sin fin, pero también una expansión correlativa de los riesgos. En otras palabras: La mutación que acaba de apoderarse de la humanidad en pocos siglos, y que la sacude en este preciso momento, se debe al descubrimiento por parte del hombre de una leyes de la naturaleza que parecen superarlo. ${ }^{11}$

Y nos supera, porque es nuestra época la que nos ha permitido darnos cuenta de que nos movemos en una tercera roca frente al sol, en un sistema solar a la orilla de una galaxia, en un universo donde existen alrededor de cien mil millones de galaxias parecidas. En el ámbito de la materia sondeamos distancias de una cienmillonésima de milmillonésima de centímetro y no dejamos de descubrir nuevos fenómenos a medida que profundizamos en ella. Es decir, no enseñar bien física, matemáticas y filosofía puede ser un acto bárbaro e inhumano.

Porque como decía el viejo Einstein, lo más incomprensible del universo es que se deja comprender. Esta es la realidad que ha rodeado desde hace diez mil años la idea del hombre, una construcción que se funda sobre el abismo, un mundo entre dos infinitos y el cual está estructurado por una leyes que pertenecen al orden del espíritu. Por ello, la maravilla de la historia de la ciencia es que muestra que los esfuerzos humanos puedan acceder a las leyes, que son en cierto modo, la recompensa de un trabajo colectivo que busca sólo la verdad. Dios no es malvado porque lo extrahumano que se encuentra ahí consiente en que se manifiesten sus leyes.

El ideal y la realidad del hombre se construyen paralelamente en la imaginación y en la realidad, con creencias y con prácticas sociales, con tradiciones y rituales, con mediciones y con demostraciones, pero a partir del siglo xVIII, dimos un gran salto, tanto en la comprensión de la naturaleza y sus leyes, como con una idea nueva de hombre. Primero fue la de la gravitación universal, las fuerzas débiles y fuertes, luego vino el encuentro con electromagnetismo, pero lo que marcó el

10 Ulrich Beck, afirma que la forma de operar conocimiento y experimentación es lo que intensifica el riesgo, porque la verificación sigue a la aplicación, y la producción precede a la investigación. El dilema en el que los megapeligros han precipitado a la lógica científica se aplica indiscriminadamente; es decir, en los experimentos nucleares, químicos y genéticos la ciencia se cierne ciegamente sobre el límite de las amenazas. La sociedad del riesgo global pp 95.

11 George Charpak y Roland Omnès, Sed sabios, convertíos en profetas, Anagrama, Barcelona, 2005 pp 59 
siglo XIX fueron tanto las leyes de la evolución descubiertas por Darwin comon las leyes de la termodinámica.

La primera sugiere una constante tendencia, a largo plazo hacia la mezcla, hacia la diversificación de las especies y hacia la complejidad de la vida orgánica de la naturaleza. Por su parte los principios de la termodinámica sugieren una constante tendencia ${ }^{12}$ al aumento de la entropía energética en un universo en el que la cantidad de energía está dada y sólo varía su forma de aprovechamiento. La formulación científica de ambos procesos sugiere un mundo progresivamente desantropomorfizado: el ser humano es parte de un continuo físico-químico y biológico-social ampliamente dependiente de la naturaleza en su conjunto. La continuidad de lo que representa nuestro estar en el mundo como parte de la naturaleza viene dada por la comprobación, que se hizo en el siglo XIX, de que descendemos de otros animales superiores en un universo que tiende hacia el equilibrio termodinámico, esto es, al aumento del desorden entrópico.

Y en este desencuadre entre la naturaleza y la acción del hombre nos encontramos en algo que históricamente hemos dado en llamar la modernidad, en la cual el accidente se convierte en una norma. La crisis y la urgencia plantean los riesgos que anuncian y potencian síntomas de desestabilización social constante en todas las escalas sociales. El escenario incorpora como dosis habitual la impunidad y la barbarie desde el contexto mundial, hasta el nivel local. Aparece la incertidumbre, tiempos presentes y futuros se conjugan con el alto riesgo. En nuestra época los bienes se convierten en desechos: los cultivos en aguas residuales, el uranio en residuos radiactivos, el petróleo y el cloro en dioxina, los combustibles fósiles en dióxido de carbono. En la modernidad al final del camino son siempre los desechos los que acompañan el alma de un hombre agotado y exausto de una embriaguez de posesión, dominio, crimen y violencia. Pareciera que este proyecto histórico, por haber negado u ocultado las consecuencias y costos indeseables derivados de una depredación y un ataque a los procesos cíclicos de la naturaleza, nos presenta dificultades y situaciones imprevistas que nos exigen cuestionar todos nuestros dispositivos y nuestras aproximaciones culturales a la naturaleza y a la vida. Se nos ha desdibujado la idea de hombre que construyó el humanismo clásico.

Estamos ante un asunto de suma importancia, porque se trata de recuperar la dignidad humana perdida. Por eso en 1979, el filósofo y teólogo protestante

12 Un juego de rompecabezas en su caja, tiene una sola forma de estar en orden para que las piezas hagan una figura y tengan un sentido, pero tiene muchas formas de estar en desorden. Este ejemplo nos lo brinda Sthepen Hawkins, en su hermoso libro La historia del Tiempo, Edt. Crítica, Barcelona 1996. 
alemán Hans Jonas (1903-1993) alumno de Edmund Husserl (1859-1938) y de RudolfBultmann (1884-1976) propone una "ética para la civilización tecnológica". El prefacio de su libro - El principio de responsabilidad — inicia con estas líneas: El Prometeo definitivamente desencadenado, al cual la ciencia le confiere fuerzas jamás hasta ahora conocidas y a la economía su impulso desenfrenado, reclama una ética que, a partir de interacciones sea libremente consentida y acordada, impida al poder del hombre, convertirlo en una maldición para sí mismo...La sumisión de la naturaleza destinada al bienestar humano ha implicado — por la desmesura de su éxito-, que se amplíe esa sumisión a la naturaleza humana. El hacer del hombre constituye hoy el mayor desafío que el ser humano haya jamás tenido en la historia. ${ }^{13}$

Jonas considera que debe transitar y llevar una heurística del miedo que se encuentra en las redes sociales a una ética de la responsabilidad. En cierto sentido podríamos apuntar que su obra retoma la estafeta del filósofo Ernest Bloch (1885-1977), que con su obra El principio de esperanza contribuyó a enfrentar con optimismo una de las épocas más violentas de la historia humana, a partir de otorgarnos una obra humanista en el marco del marxismo más inteligente del siglo pasado, que apuesta por un mundo en el cual ni la naturaleza ni los hombres sean sometidos por una técnica fuera de control social.

Otra obra que describe la trampa del mundo moderno a través de la técnica es el libro de Jean-Jacques Salomón Sobrevivir a la ciencia en el cual escribió: El avatar contemporáneo de Prometeo es el "investigador", el científico, el ingeniero, el técnico, cuyos trabajos están orientados —en el seno de los laboratorios públicos y privados - a multiplicar los descubrimientos y las innovaciones. Este Prometeo, escribe, es el más dinámico que nunca y mejor armado desde el inicio de la industrialización para ejercer su genio inventivo. Por lo tanto "el campo de sus actividades, por más vasto que sea, está de ahora en adelante limitado: Prometeo debe contar no solamente con la resistencia... de las cosas, de la materia, de la naturaleza, sino principalmente con la resistencia de los hombres, de las instituciones, de la sociedad, agujero tapado, la ciencia está atrapada en sus propias trampas y nada puede ceder al embriagamiento de utopías del progreso sin saber cual es el costo." 14

Denunciar la"actitud prometéica"del hombre, como lo hace el filósofo, implica tomar posición en un debate abierto en los términos en los que Martín Heidegger

13 Hans Jonas, Le principe responsabilité: une étique pour la civilization technologique. Edt. Du Cerf, París 1990.

14 Salomon, Jean-Jacques. Survivre á la science, Une certaine idée du futur. Albin Michael, París, 1999. 
(1889-1976), en 1954 convino en llamar la cuestión de la técnica. La esencia de la técnica no tiene nada de técnico, ella es metafísica. Ella ubica la existencia a disposición de la acción humana que apunta al dominio y subordinación de la naturaleza. Y esta puesta a disposición, en donde las ciencias humanas racionalizan los procedimientos y amplifican los resultados, amenaza al planeta a una desvastación total.

Dignidad, libertad, igualdad, elementos que forjan la idea del perfeccionamiento humano desde la Antigüedad, el Renacimiento y el siglo XVIII. Estuvieron en el corazón y el espíritu de los hombres durante las grandes transiciones urbanas, nutrieron las revoluciones políticas, fueron pilares de la fundación de la mayor parte de los estados nacionales. Esos valores se enfrentan hoy a escalas demográficas y niveles de complejidad que obstaculizan e impiden la realización de los sueños de la llustración y más bien sugieren una pérdida de control y rumbo del destino humano. Hoy, la verdad acaba siendo únicamente producto de interpretación de interpretaciones. La opinión pública ha desplazado a la voluntad general de Rousseau. En lugar de pueblo lo que vemos son masas fácilmente manipulables, sin tiempo de socializar, pensar o leer libros. La abundante información que ofrece la Internet, contrasta con la total escasez de tiempo del individuo medio de las grandes ciudades para digerir el caudal de opciones comunicativas.

Si reconsideramos y cuestionamos que la línea de desarrollo científicotécnico de Occidente no puede llegar a convertirse en modelo único universal, (en proyecto de la especie), por el que supuestamente tendrían que transitar todas las culturas del mundo, por razones ambientales y límites de los propios ecosistemas, la tarea del humanismo tendría que desplegar su cuestionamiento a la carga antropológica del trabajo y a la organización biosocial del hombre, para reubicar los fines y los medios. La tarea inmediata es valorar más el estudio de la complejidad social desde la perspectiva sociológica y filosófica; habrá que repensar el papel del Estado para regular más al mercado y desde la participación social construir mecanismos sociopolíticos que orienten el proceso a favor de intereses auténticamente humanos, estos son los que encarnan los más desfavorecidos por la historia, los que Franz Fanon llamó los condenados de la tierra con la tierra misma. 


\section{BIBLIOGRAFÍA}

Axelos, Kostas. Horizons du monde, Les éditions du minuit, París, 1974.

Arendt Hannah, Condition de l'homme moderne, Calmann-Levy, París, 1983.

Ayala Blanco, Luis A. Marroquin C. El poder frente a sí mismo. Sexto piso. México 2003.

BACHELARD, Gaston, La formación del espíritu científico, Fondo de Cultura Económica, México, 1989.

BAUER, Martín. Resistance to new technology, nuclear power information technology and biotechnology. Cambridge University Press, 1995.

BECK, Ulrich. La sociedad del riesgo, Paidós, Barcelona, 1998.

BeriaIN, Josexto. La lucha de los dioses en la modernidad. Anthropos, Barcelona, 2000.

-(comp.) Giddens, Z. Bauman y N. Luhmann. Las consecuencias perversas de la modernidad, Antrhopos, Barcelona, 1996.

BERLIN, Isaiah. El sentido de la realidad, sobre las ideas y su historia. Taurus, Madrid,1998. 1992.

Bılbao Andrés. Las raíces teológicas de la lógica económica. Elementos para una crítica al liberalismo. Centro de Investigaciones Interdisciplinarias en Ciencias y Humanidades. UNAM, México, 1999.

BLoCH, Ernst. El principio de esperanza. Aguilar, Madrid, 1977.

BoHme Gernot y Hartmut, Fuego, agua, tierra y aire, una historia cultural de los elementos. Herder, Barcelona, 1998.

BUNGE, Mario, La relación entre la sociología y la filosofía. EDAF, Ensayo, Madrid, 2000.

Broncano Fernando, Mundos artificiales, filosofía del cambio tecnológico. Paidós, UNAM, México, 2000.

CabreRa Castro, Miguel A. Historia a debate, pp. 209. citado por Gabriel Vargas Lozano en "El fin de la historia". Revista Estudios de Filosofía práctica e historia de las ideas. Año 3, No 3. Dic. 2002.

CalASSO, Roberto, La ruina de Kasch. Anagrama, Barcelona ,1993. Los cuarenta y nueve escalones, Ed. Anagrama, Barcelona, 1995.

CAso, Antonio, "El peligro del hombre", en Obras Completas, Tomo VIII, UNAM, 1975. 
EnzensBerger, Hans Magnus, Los elíxires de la ciencia, Anagrama, Barcelona 2002.

Fernández-Armesto, Felipe, Civilizaciones, la lucha del hombre por controlar la naturaleza, Taurus, Bogotá, 2002.

Fernández-Rañada Antonio, Los científicos y Dios, Ediciones Nobel. Madrid, 1996.

Feyerabend, Paul K., Ambigüedad y armonía. Paidós, Barcelona, 1999.

FinkIeLKRAUt, Alain La derrota del pensamiento, Anagrama, Barcelona, 1987.

Foucault, Michel, Defender la sociedad. FCE, México, 2001.

Frankel, Boris, Los utópicos postindustriales, Ediciones Alfonso El Magnánimo, Valencia, 1987.

Funke, Gerhard, Fenomenología: ¿Metafísica o método?, Monte Ávila Editores, Venezuela, 1987.

GABÁs, Raúl, J. Habermas: dominio técnico y comunidad lingüística. Ariel, Barcelona, 1980.

Gadamer, Hans-George, La herencia de Europa. Península, Barcelona, 1990. Elogio de la teoría, Península, Barcelona, 1993.

Gellner, Ernest, El arado, la espada y el libro, Península, Barcelona, 1994.

GIDDENS, Anthony, Capitalismo y la moderna teoría social. Idea Books, 1998.

Hawkins, Stephen, Historia del tiempo, Ed. Crítica, Barcelona, 1996.

JonAs, Hans, Le principe responsabilité: une étique pour la civilization technologique, Ed. Du Cerf, París, 1990.

LeCourt Dominique, Prométhee, Faust, Frankenstein, Fundements imaginaires de l'éthique, Synthélabo, Paris, 1996.

Marcel Gabriel, Los hombres contra lo humano, Caparrós Editores, Madrid, 1951. MARX, Karl y Engels Federico, Obras Escogidas, Edt. Progreso y Cultura Popular. México, 1965.

MARX, Karl, Miseria de la filosofía, Ed. Orbis, Barcelona, 1984.

Mumford, Lewis. El Pentágono del poder. El mito de la máquina (dos). Edit. Pepitas e calabaza, Madrid, 2011.

OMNĖs Roland y Charpak George, Sed sabios, convertíos en profetas, Anagrama, Barcelona, 2005.

Salomon, Jean-Jacques. Survivre á la science, Une certaine idée du futur, Albin Michael, París, 1999. 